\title{
Mobile Communication and its Adverse Effects
}

\author{
Kul Prasad Dahal \\ Department of Physics, Prithvi Narayan Campus, Tribhuvan University, Pokhara, Nepal \\ dahalkp@yahoo.com
}

\begin{abstract}
Mobile phone became almost essential part of daily life for all generation of people. It functions with the help of transmission of electromagnetic waves from towers to the cell phones in the micro wave frequency region. The energy carried by the waves is not only useful for mobile communication but also produce adverse affects on the users' health as well as to all living beings which are in the radiation area. The paper aims to discuss some of the possible dark side of health concern by the usage of cell phone and radiation from the towers. It also aims to suggest the possible remedies to minimize the health problems.
\end{abstract}

Keywords: electromagnetic radiation, radiation hazard, adverse effect, SAR.

\section{INTRODUCTION}

The increased use of mobile phone by the public is accompanied by a wave of contradictory reports about the possible health effects, which result from exposure to electromagnetic fields (EMF) by the phone's user and neighbors of stations. Given the immense numbers of users of mobile phones, even small adverse effects on health could have major public health implications. Mobile phones also called cellular phones are becoming an integral part of modern telecommunications in the twenty first century. Mobile telephones became available from some telephone companies in the 1940s. Early devices were bulky and consumed high power and the network supported only a few simultaneous conversations. Engineers from Bell Labs began work on a system to allow mobile users to place and receive telephone calls from automobiles, leading to the inauguration of mobile service on June 17, 1946 in St. Louis, Missouri, USA. The weight of a latest model, presented in 1961, in the then USSR, was only $70 \mathrm{~g}$ and it freely took place on a palm. Modern cellular networks allow automatic and pervasive use of mobile phones for voice and data communications. In many countries, over half the population already uses mobile phones and market is still growing rapidly.

Cell phone usage includes help people feel safe, financial benefits, manage time efficiently, and keep in touch with friends and family members. Mobile phone enables people to communicate when, where and with whom they wish. People have various feeling and attitudes towards cell phone usage. For many parents, they offer an important means of keeping in touch with their children as they travel to and from school, sporting activities or meeting with friends. Through the global wireless network, participants scattered across a city or the world can easily coordinate activities and upload data to servers that can process it and integrate it with other data, such as GIS map layers and weather reports, that a variety of organizations publish on the web. Mobile phones are not only used for telephoning, but also for sending text messages, transferring data listening to music, playing games and watching videos, thereby exposing different body parts to electromagnetic waves. On the other hand Telehealth technology could encourage better doctorpatient interaction regarding patient symptoms and quality of life monitoring. This may be a better way of communication between doctor and patient for better health condition and curing.

The rapidly evolving mobile phone technology raised public concern about the possibility of associate adverse health effects. The telecom sector is providing millions of jobs in the world but it is also giving cancer and other serious health problem to billions of people besides causing harm to birds, animals, plants etc. to the living world. It is not only fastest growing industry but it is also creating 
fastest growing health problems. Many people are increasingly concerned about the possible health effects due to frequent, long term use of cell phone and the radiation. As year after year immense numbers of users of mobile phones, even small adverse effects on health could have major public health implication. Traffic accidents caused by using telephone during driving are another public challenge. Mobile phones are often prohibited in hospitals and on airplanes, as the radiofrequency signals may interfere with certain electro-medical devices and navigation systems.

In addition to the context of Nepal, as six voice telecom operators, more than 30 ISPs, more than 320 FM stations, more than 35 Television channels and one AM radio are already in operation, it is already high time to explore the signal level and develop the guidelines to minimize the health hazard from the electromagnetic radiation of wireless communication.

\section{MOBILE PHONE GENERATION (G)}

The nomenclature of the cellular wireless generations $(\mathrm{G})$ generally refers to a change in the fundamental nature of the service, non-backwards compatible transmission technology and new frequency bands. New generations have appeared about every ten years since the first move from 1981 analog (1G) to digital (2G) transmission in 1992. This was followed in 2001 , by $3 \mathrm{G}$ multi-media support, and in 2011 by 4G, which refers to all-IP switched networks, mobile ultra-broadband.

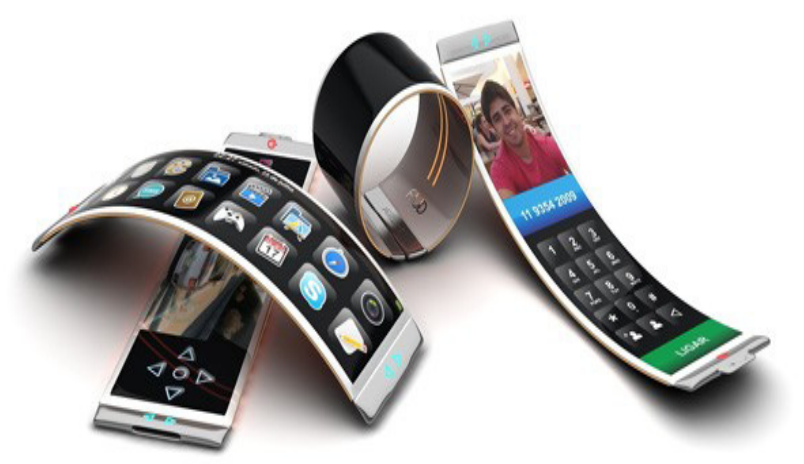

Fig. 1. Future generation cell phones
First generation refers to the analog phones as they were first introduced for mobile cellular technology. Cell phones began with $1 \mathrm{G}$ and signify first generation wireless analog technology. $2 \mathrm{G}$ signifies second generation wireless digital technology. The second generation (2G) digital cellular network includes digital phones with added fax, data and messaging services. It is fully digital $2 \mathrm{G}$ networks which first commercially began on the Global System for Mobil Communications (GSM). The generation 2.5G wireless technology is as an interim step up from a stepping stone that bridged $2 \mathrm{G}$ to $3 \mathrm{G}$ wireless technology. Another generation $3 \mathrm{G}$ is the third generation of mobile phone with further advanced features, standard and technology. 3G technologies have enabled faster data transmission speeds, greater network capacity and more advanced network services. The generation 3.5 is an interim or evolutionary step to the next generation of cellular technology, not an officially recognized standard. Another generation $4 \mathrm{G}$ is the term used to refer to the fourth generation of mobile wireless services, the latest generation in the mobile market. Based on the above observations, a new generation of $5 \mathrm{G}$ standards may be introduced approximately in 2020 ? Since a new mobile generation has appeared approximately every 10 th year.

\section{MOBILE PHONE FREQUENCY}

Mobile phones are low-powered radiofrequency transmitters, operating at frequencies between $450 \mathrm{MHz}$ to $2700 \mathrm{MHz}$ with peak powers in the range of 0.1 to 2 watts. Frequency is the number of cycles per second that energy wave oscillates, also expressed in cycle per second (cps). Cell phone communication is carried by electromagnetic wave, basically microwaves. The cell tower transmits in the frequency range of $869-894 \mathrm{MHz}$ (CDMA), 935-960MHz (GSM $900)$ and $1805-1880 \mathrm{MHz}$ (GSM 1800). The third generation $3 \mathrm{G}$ transmits in the frequency range of 2110-2170 MHz. The Wireless Fidelity (Wi-Fi) radiation lies $22.4-2.5 \mathrm{GHz}$. For the accessible mobile network majority of towers of the sources are mounted near in the densely populated area. 


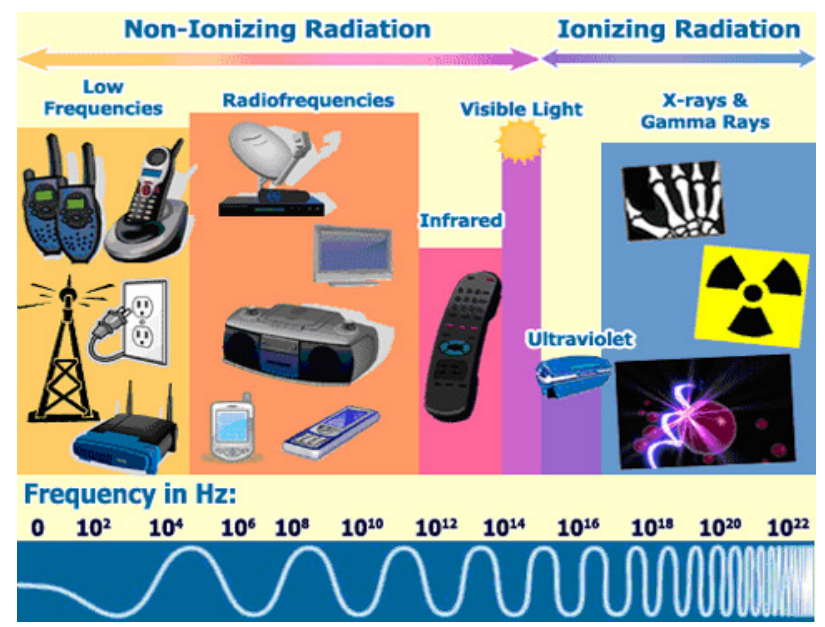

Fig 2: diverse uses of electromagnetic radiation

Besides mobile communication, the radio frequency in the microwave and radio spectrum is used in a number of practical devices for professional and home use. The cordless phones operating at a wide range of frequencies, remote control devices for opening gates, portable two-way radio communication devices, such as walkie-talkies ,wireless security (alarm) systems, wireless security video-camera, radio links between buildings for data communication, baby monitors, smart meters and so on. These devices are in frequent touch with the concerning people as well as nearby public. There are other kinds of ionizing radiation such as X-ray or gamma rays, relatively more harmful to our body. Unlike ionizing radiation radio frequency fields cannot cause ionization or radioactivity in the body.

\section{SCENARIO OF CELL PHONES USERS}

In the year 2000, there were an estimated 500 million mobile phone users worldwide. There were about 3.3 billion users in 2009. According to the International Telecommunications Union, the number of cellphone subscriptions has reached 5 billion in mid 2010. Currently, over six billion people using mobile phone. In most of the countries, percentage of cell phone users is less than the total population. Whereas in some countries like Russia, Saudi Arab and Hong Kong, people have been using more than single cell phone, percentage exceeds more than
150. People in the countries like Germany, Brazil, Italy, United Arab Emirates, Bulgaria, Singapore, Lithuania, Estonia and many others, cell phone use percentage exceeds more than hundred, lies between 100 to 150 . The cell phone users in China and India are 85 percentage and 70 percentage respectively. Nepalese cell phone users are 68 percentages.

Table 1: Population of human beings and mobile phones - a brief scenario

\begin{tabular}{|c|l|l|l|l|l|}
\hline S N & Rank & Country & $\begin{array}{c}\text { Number } \\
\text { of mobile } \\
\text { phones } \\
\left(\times 10^{6}\right)\end{array}$ & $\begin{array}{c}\text { Total } \\
\text { Pop. } \\
\left(\times 10^{6}\right)\end{array}$ & $\begin{array}{c}\text { Phone } \\
\text { users \% } \\
\text { of Pop. }\end{array}$ \\
\hline 1 & --- & World & $\begin{array}{l}\text { Over } \\
6000.00\end{array}$ & 7,012 & 87.00 \\
\hline 2 & 01 & China & 1150.00 & 1349.58 & 85.21 \\
\hline 3 & 02 & India & 861.66 & 1220.20 & 70.42 \\
\hline 4 & 03 & USA & 327.57 & 310.86 & 103.90 \\
\hline 5 & 04 & Brazil & 263.04 & 192.37 & 136.70 \\
\hline 6 & 05 & Russia & 256.11 & 142.90 & 153.50 \\
\hline 7 & 07 & Pakistan & 122.06 & 178.85 & 68.83 \\
\hline 8 & 42 & Nepal & 18.24 & 26.62 & 68.50 \\
\hline 9 & 44 & Srilanka & 17.35 & 21.00 & 80.95 \\
\hline
\end{tabular}

Mobile telephony is growing very quickly in Nepal too. There were about 1.0 million subscribers in the year 2008 and the number increased to 13.6 million by 2011. The number is expected to exceed 25 million subscribers.

\section{BASE STATIONS:}

The mobile phone towers and their transmission power is designed in such a way that it covers a distance of at least few kilometers, implying that a mobile phone at that distance should be able to transmit and receive enough signals for easy communication. The cell phone holders around the tower will receive ten thousand time stronger signal than it is required for mobile communication.

Base stations are low-powered radio antennae that communicate with user handsets. Given the immense number of users of mobile phones, even 
small adverse effects on health could have major public health implications. Several important considerations must be kept in mind when evaluating possible health effects of radio frequency fields. These are low powered microwave electromagnetic radiation. People living 50 to 300 meter radius is in the high radiation zone. Negative impact is prompt if there is direct facing and at the similar height of the tower, especially to those who live in tall multistory buildings near the transmitting towers.

At many places, cell phone towers are mounted on the roof top of the residential/commercial buildings. Even though antenna radiates less power vertically down but the distance between the antenna and top floor is usually a few meters, so the radiation level in the top two floors remain very high. However the concrete wall provides some attenuation and hence actual power should be less than theoretically calculated power.

\section{SPECIFIC ABSORPTION RATE (SAR)}

Different cell phone models emit different amounts of radiations. More the radiation emitted by the cell phone greater will be degree of health hazards. So, one of the ways to reduce radiation exposure is to purchase a cell phone with a lower SAR value. The radiation level differs from mobile phone set model and manufacturing company. It is a number that indicates how much radiation is absorbed by the human body when the handset is being used at maximum power. Its unit is watts/kilogram $(\mathrm{W} / \mathrm{kg})$. The SAR values are useful, but they are bound to increase as cell phone become more powerful and add new features and applications. In the US the maximum SAR limit for cell phone is $1.6 \mathrm{~W} / \mathrm{kg}$, which amounts to six minutes usage per day. It has a safety margin 3 to 4 , so even in an extreme case; a person should not use cell phone for more than 18 to 24 minutes per day. To the excessive use of mobile phone (i.e. half an hour per day about 8 to 10 years) have double to quadruple the risk of brain tumor. In a study in Germany, a threshold of $1,000 \mu \mathrm{W} / \mathrm{m}^{2}$ (micro-watt per square meter) was pointed out for non-thermal biological effects, and a further safety factor of 10 was recommended for pulsed radiation sources as cellular phone base stations for longterm exposure, reporting that the power densities should not exceed $100 \mu \mathrm{W} / \mathrm{m}^{2}$ Prolonged exposure to microwave radiation can lead to macroscopic and microscopic damages. Any cell phone at or below these SAR levels is a safe phone, as measured by the standards.

Table 2: SAR values of some of the mobile phones from different manufacturers

\begin{tabular}{|c|l|l|c|}
\hline S N & \multicolumn{1}{|c|}{ Brand } & Model No & $\begin{array}{c}\text { SAR rate } \\
(\mathrm{W} / \mathrm{Kg})\end{array}$ \\
\hline 1 & Alcatel & 153 & 0.77 \\
\hline 2 & $\begin{array}{l}\text { Sony/ } \\
\text { Ericsson }\end{array}$ & 1200 & 1.39 \\
\hline 3 & LG & C1100 & 1.12 \\
\hline 4 & Mitsubisi & Galaxy & 0.93 \\
\hline 5 & Motorola & 2288 & 0.66 \\
\hline 6 & Nokia & THR850 & 0.35 \\
\hline 7 & Panasonic & A100 & 0.743 \\
\hline 8 & Philips & 355 & 0.662 \\
\hline 9 & Samsung & SGHX600 & 0.842 \\
\hline 10 & Siemens & U15 & 0.35 \\
\hline 11 & Sharp & TG700 & 1.01 \\
\hline 12 & Swisscom & Trend G366 & 1.05 \\
\hline
\end{tabular}

In response to public and governmental concern, World Health Organization established the International Electromagnetic Fields (EMF) Project in 1996 to assess the scientific evidence of possible adverse health effects from electromagnetic fields. In addition, the International Agency for Research on Cancer (IARC), a WHO specialized agency, has reviewed the carcinogenic potential of radiofrequency fields, as from mobile phones in May 2011.Various governments have adapted the SAR limit according to their convenience. 
Table 3 : international standards SAR limit.

\begin{tabular}{|l|l|l|l|}
\hline \multicolumn{1}{|c|}{ Region/ Country } & \multicolumn{1}{|c|}{$\begin{array}{c}\text { Reference to SAR } \\
\text { measurement protocol }\end{array}$} & \multicolumn{1}{|c|}{ Reference to SAR limit } & \multicolumn{1}{c|}{ Limit } \\
\hline Europe & European Specification & ICNIRP Guidelines 1998 & $2.0 \mathrm{~W} / \mathrm{Kg}$ in $10 \mathrm{~g}$ of tissue \\
\hline $\begin{array}{l}\text { Australia, Canada, } \\
\text { Newzealand }\end{array}$ & $\begin{array}{l}\text { Australian Communications } \\
\text { Authority(ACA) Standard }\end{array}$ & $\begin{array}{l}\text { Australian Standard AS/ } \\
\text { NZS } 2772.1\end{array}$ & $1.6 \mathrm{~W} / \mathrm{Kg}$ in $1 \mathrm{~g}$ of tissue \\
\hline USA & $\begin{array}{l}\text { Federal Communications } \\
\text { Commission (FCC) }\end{array}$ & American Standard ANSI & $1.6 \mathrm{~W} / \mathrm{Kg}$ in $1 \mathrm{~g}$ of tissue \\
\hline India & $\begin{array}{l}\text { Federal Communications } \\
\text { Commission (FCC) }\end{array}$ & American Standard ANSI & $1.6 \mathrm{~W} / \mathrm{Kg}$ in $1 \mathrm{~g}$ of tissue \\
\hline Sri lanka & European Specification & ICNIRP Guidelines 1998 & $2.0 \mathrm{~W} / \mathrm{Kg}$ in $10 \mathrm{~g}$ of tissue \\
\hline $\begin{array}{l}\text { Japan, South } \\
\text { Korea }\end{array}$ & European Specification & ICNIRP Guidelines 1998 & $2.0 \mathrm{~W} / \mathrm{Kg}$ in $10 \mathrm{~g}$ of \\
\hline
\end{tabular}

7. NEGATIVE HEALTH CONSEQUENCES OF MOBILE PHONE RADIATION:

The use of cell phone as well as base stations may be the cause of several adverse effects to human being as well as all living world.

\subsection{Thermal and non-thermal effects}

The known biological effects associated with these fields vary with the radio frequency and intensity of exposure. Intensity varies both with the amount of power emitted by the energy source and the distance of the individual from the source. Different regions of electromagnetic spectrum may affect biological systems to different extent. The effect of radio frequency on living organisms may be didactically divided into thermal effects and non thermal effects. Thermal effects are the best known effects. They result from water molecule polarization as electromagnetic waves course through tissues and produce heat. In the case of a person using a cell phone, most of the heating effect will occur at the surface of the head, causing its temperature to increase by a fraction of a degree. Thus radiation can elevate body temperature similar to microwave oven. With a cell phone in our pocket or by our head, slight temperature increases might disrupt cellular functioning.

Due to the prolong use of cell phone, people have experienced that their ear gets warm after about 20 minutes continuous use of cell phone. The microwave radiation from the cell phone heats the blood in the ear lobe and its temperature increased by nearly $1.80^{\circ} \mathrm{F}$, causing the normal body temperature of $98.40^{\circ} \mathrm{F}$ to rise to $100.20^{\circ} \mathrm{F}$. This leads to ear pain, haring loss and ear tumor. On the other hand when we continuously use cell phone for about 20 minutes, temperature of ear lobes increases by $1{ }^{\circ} \mathrm{C}$.

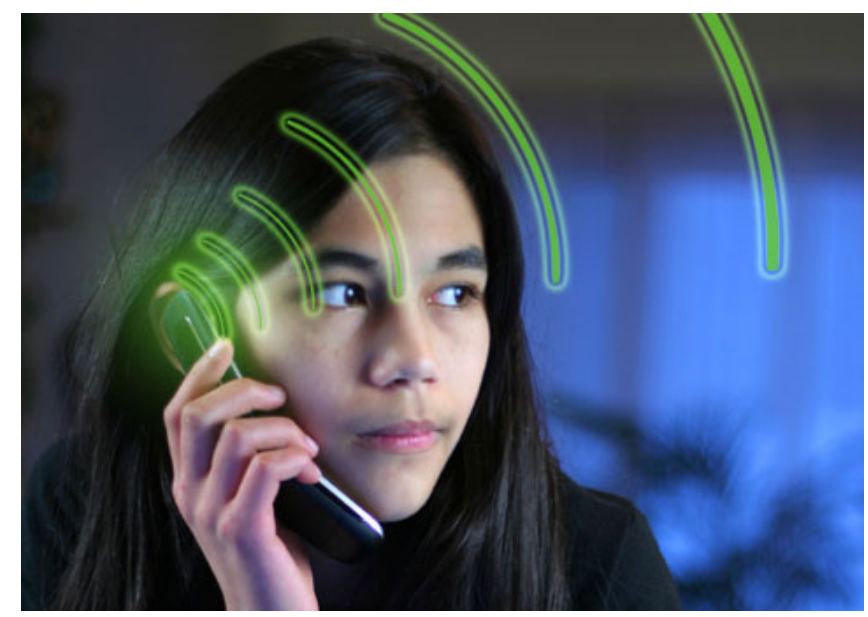

Fig 3: Emission of radiation from cell phone while in use

It may cause irreversible hearing loss. Finally, it leads to ear tumor

Non-thermal effects take place with no temperature change in biological tissues. These effects include electrical force induction and possibly an increase in heat shock protein synthesis in cells resulted in increased levels of glucose metabolism. Radiofrequency energy can alter cell membrane permeability, the movement of calcium ions, cell excitability, free radical production, blood-brain 
barrier integrity, and the stress response and/or neurotransmitter release.

\subsection{Effects on fertility:}

The electromagnetic radiation(EMR) emitted by cellular phone influences human sperm motility. In addition to these acute adverse effects of EMR on sperm motility, long-term EMR exposure may lead to behavioral or structural changes of the male germ cell. These effects may be observed later in life.

\subsection{Electromagnetic hypersensitivity}

The term electromagnetic hypersensitivity (EHS) if often used to denote a phenomenon where individuals experience adverse health effects while using or being in the vicinity of electric, magnetic, or electromagnetic field sources and devices, and when the individuals themselves attribute their symptoms to these sources and devices. Symptoms experienced vary substantially between different individuals. Some users of mobile handsets have reported feeling several unspecific symptoms during and after its use. The effects may be burning and tingling sensations in the skin of the head and extremities, fatigue, sleep disturbances, dizziness, loss of mental attention, reaction times and memory retentiveness, headache, tachycardia and disturbances of the digestive system.

\subsection{Possible hazards on Human beings}

From World Health Organization (WHO) report evidence as found of an increase in glioma and acoustic neuroma brain cancer for excessive cell phone users. Exposure to electromagnetic radiations reduces melatonin in animal and humans. Daily cellular phone use of more than 25 minute per day over years may lead to reduced melatonin production. Melatonin is the powerful antioxidant, antidepressant and immune system enhancer that regulates our circadian rhythm. Reduction of melatonin causes, sleep disturbance chronic fatigue, depression, cardiac reproductive and neurological diseases. Some other adverse affects are loss of appetite, damage of DNA, risk of cancer, arthritis, schizophrenia, increased eye stress, renal impairment, Alzheimer's,Parkinson disease and increased risk of childhood leukemia.

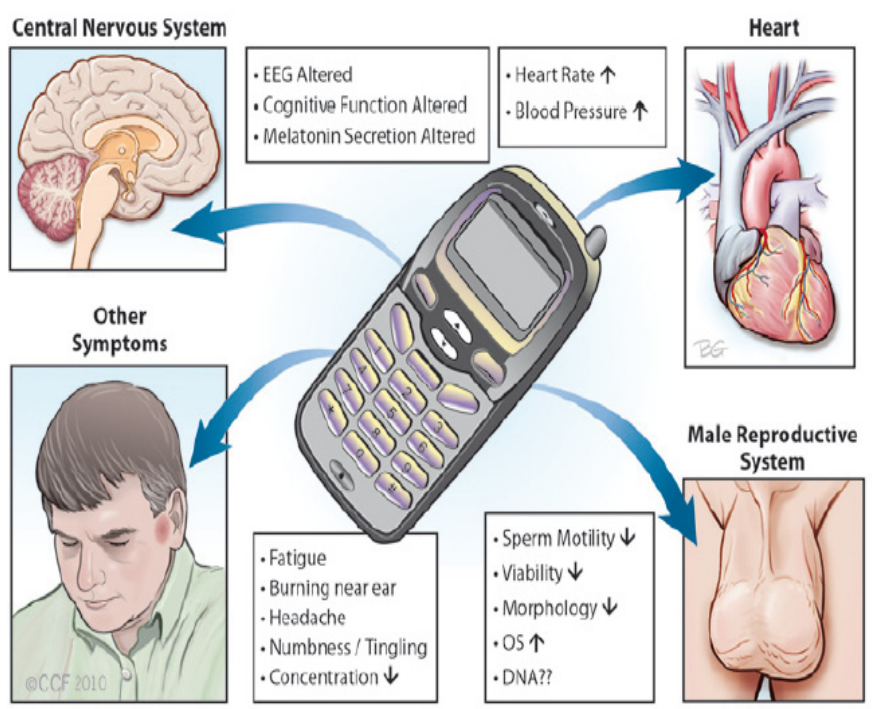

Fig 4: various radiation hazards from cell phones

The increased risk of brain cancer and acoustic neuromia is due to prolong use of mobile phones for more than ten years.

The risk is highest on the same side of the head where the mobile set is held.

Radiation from the cell phone also dries up the skin, the fluid in the nearest eye and it also penetrates the skull and heats the brain. Consequently it brings sleeping disorder, headache, irritation, loss of memory, lack of concentration and ultimately brain tumor. A research report found a direct association between the duration of cell phone usage among men and a decrease in semen quality, sperm count, mortality, viability and normal morphology. Signal generated by mobile phones causes electromagnetic interference with the device like pace makers, Implantable Cardiovascular Defibrillators(ICDS). So their functions may be improper.

Moreover Telecommunication workers who spend time at a short distance from the active equipment, for the purposes of testing, maintenance, installation, etcetera, may be at risk of much greater exposure than the general population.

\subsection{Effects of Radiofrequency on plants, birds and animals}

The birds are seen very rear near the cell towers. 
The microwave radiation emitted from the towers produce heating effect on the body of birds. The birds have more volume and less weight, so heating effect is very fast. To avoid such happening, birds try to keep themselves away from the cell tower as far as possible. Bees and birds are interfered with navigation and reproduction. Bees cannot find their way back to hive due to disruption in intercellular communication. Bees are vital pollinators for agriculture. With vanishing of bees, a major food crisis could ensue .The effect of microwave from the cell tower is equally affected to big sized animals like cow, buffalo. It is observed in them, decreased milk production, reproduction and developmental problems as well as decline in overall health. The domestic animals like Sheep, dogs, cats', rabbits living near base stations are also affected. As like the animals, the effect of radiation from cell tower equally affects the nearby plants. Output of most of the fruit bearing trees drastically reduced to less than $5 \%$ after 2.5 years at a place consisting of crowded cell tower installation.

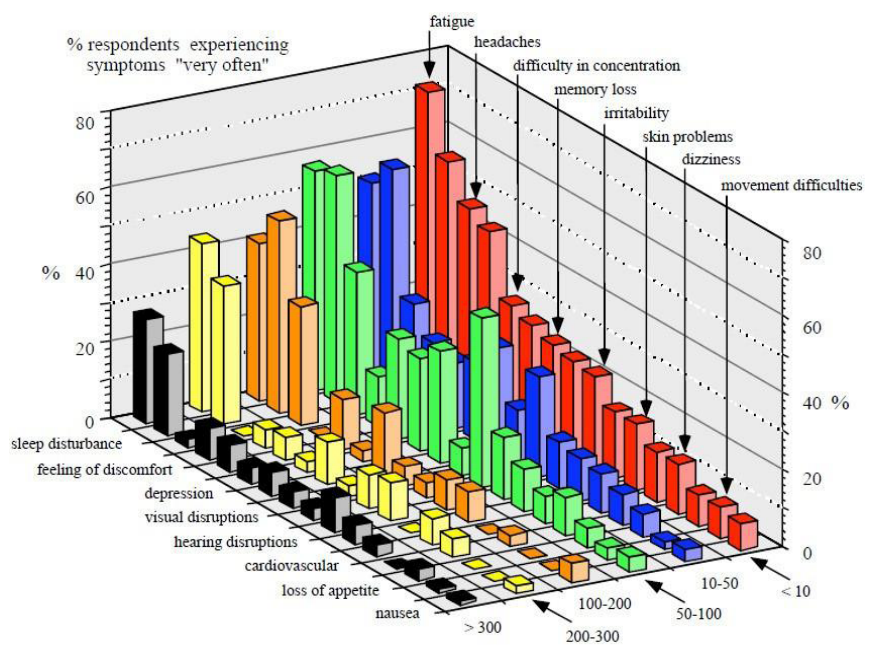

Fig 5: Electromagnetic Hazards According to Sanitini 2002.

When we are exposed to solar radiation, heating our body takes place from outside to inside. Heating of skin is more affected than the internal parts of our body. For the compensation of heat, sweating in our body takes place. On the other hand, when our body is exposed to microwave radiation, its heating effect is from inside to outside .It produces internal heating effect earlier. So heat is trapped inside our body. Unnecessary head is trapped in cells which may cause their damage.

\section{WHEN CELL PHONE IS NOT IN USE}

Even when the cell phones are not in use they transmit power continuosly to base station at the rate about 1 Watt per minute. If a cell phone is kept in the pocket for six hours a day, about 360 pulses of $1 \mathrm{~W}$ is absorbed by the body that is whooping 360 Watt of power. So, it is better keeping the cell phone away from the body as far as possible, even when it is not in use. The cell phone, therefore, is like a mini microwave oven which is continuously transmitting power to our body. Consequently it produces unnecessary heating to the cells of our body.

Radiations not only from cell phone we are continuously exposed but also from cell towers, wireless phones computers, laptops, TV towers, FM towers, AM towers microwave ovens etc. The human body and living beings are being suffering from manmade installation.

\section{REMEDIES TO MINIMIZE CELL PHONE RADIATION:}

\subsection{Keep a distance:}

The intensity of cell phone radiation diminishes quickly as distance from cell phone increases. The ways to keep body away from the cell phone can be done by using the wire headset, putting cell phone on speaker mode, using wireless Bluetooth headset or earpiece, which emits radiation at far lower levels than cell phones. Carrying cell phone away from the body - in a purse, briefcase or bag but not in a pocket is a safely way to keep body away from the radiation. In addition, using "hands-free" devices, keep mobile phones away from the head and our body during phone calls.

\subsection{Reducing calls:}

Radiation exposure can also be reduced by limiting the number and length of calls.

\subsection{Try texting, not talking:}

Sending a text message from cell phone, the phone sets remains away from the body as far away from the head, which helps to reduce the exposure to radiation in our body. 


\subsection{Find a strong signal:}

When a cell phone has a weak signal, it has to work harder to transmit and resulting higher burst of radiation. It is better not to try to attempt a call when the signal is weaker. Using the phone in areas of good reception also decreases exposure as it allows the phone to transmit at reduced power.

\subsection{Wait to speak and listen:}

Most cell phones emit the radiation when they first connect with the cell tower. One way to reduce exposure to cell phone radiation is to wait until the cell has been connected before one has to put the phone to the ear.

\subsection{Use the toggle method:}

Because cell phones emits significantly more radiation when they are transmitting signals than when they are receiving, one can reduce radiation exposure by holding the phone away from ear/head and bringing it close to listen. Using a headset or speaker mode is further better option.

\subsection{Use low SAR cell phone:}

The radiation hazards can also be minimized by using cell phones of low SAR value. While purchasing the cell phone in the market, the customers should be aware of this idea.

\subsection{Use line phones:}

As far as possible, house hold phone (fixed phone) is better for the purpose of communication. Possible radiation hazards can be minimized.

\subsection{Minimize the usage:}

Lowering the use of cell phone duration minimizes the radiation hazards. The body will be exposed for lesser time to the radiation.

\subsection{Cell phone user manual:}

The cell phone manufacturer should warn the customers to keep cell phone away from the body, just like warnings on cigarette packages.

\subsection{Radiation Norms:}

Stricter radiation norms

must be enforced by the concerned policy makers.

\section{CONCLUSION}

The diverse uses of electromagnetic radiation becoming an inevitable part of human being in the modern technology. We are receiving continuous radiation from cell phone towers, cell phones, wireless phones, computers, laptops, TV towers, FM towers, microwave ovens, etc. Our body is exposed to all these radiations, which are additive in nature. This does not mean that we neither have to stop living near these towers nor stop using cell phones and other accessories. As a common fact, that automobiles create air pollution and we don't stop using them. Instead solutions are to found to minimize the degree of radiation pollution. Likewise, the individual should use cell phone with great conscious of its dark sides. Moreover stricter radiation norms must be enforced by the policy makers.

\section{AKNOWLEDGEMENT}

The author aknowledge to prof. Girish Kumar, Electrical Engineering Department, IIT Bombay and Mr. Umesh Gupta, Telecom Engineer, Nepal Telecom, Pokhara for fruitful suggestions.

\section{REFERENCES}

[1] Ahlbom A., Green A., Kheifets L., Savitz D., Swerdlow A. (2004). Epidemiology of health effects of radiofrequency exposure. Environmental health perspectives 112(17), 1741

[2] Baron NS. (2010)The Dark Side of Mobile Phones. Department of Language and Foreign Studies, American University, Washington, DC. [Obtained: May 21, 2013]

[3] Elsevier : Mobile phones and health: A literature overview.

http://www.elsevier.de/zmedphys

[Obtained : May 21, 2013] 
[4] Erogul O, Oztas E, Yildirim I, Kir T, Aydur E, Komesli G, Irkilata HC, Irmak MK, Peker AF. (2006). Effects of electromagnetic radiation from a cellular phone on human sperm motility: an in vitro study. Arch Med Res.37(7):840-3.

[5] Ishii K.(2011).Examining the adverse effect of mobile phone use among Japanese adolescents. Keio Communication Review No.33,: 69-83

[6] Karger CP. (2005). Mobile phones and health: a literature overview. Z Med Phys.,15(2):7385.

[7] Kumar N. and Kumar G.(2009) Biological Effects of Cell Tower Radiation on Human Body, ISMOT
[8] Kumar G (2011). Stuff you just need to know. Popular Science India; 94-95

[9] Nepal Telecommunications Authority. (2013) Consultation Paper on Guidelines on Health. Hazard due to Wireless Commu nication.

[10] Santini R., Santini P., Danze J.M., Le Ruz P., Seigne M.,(2002). Investigation on the health of people living near mobile telephone relay stations: Incidence according to distance and sex. Pathologie-biologie, 50(6): 369-73.

[11] Wikipedia, List of countries by number of telephone lines in use http://en.wikipedia. org/wiki/List_of_countries_by_number_ of_mobile_phones_in_use\#cite_note-1 [Obtained: June 4,2013] 